Research article

Lesley Farmer*

\title{
News Literacy and Fake News Curriculum: School Librarian Perceptions of Pedagogical Practices
}

https://doi.org/10.1515/opis-2019-0016

Received June 16, 2018; accepted June 3, 2019

\begin{abstract}
People need to consciously and critically analyze and evaluate mass media messages, especially in the light of increasing fake news; they need to be news literate. The logical time to start teaching such literacy is in K-12 educational settings so that all individuals have the opportunity to learn and practice news literacy. California middle and high school teacher librarians were surveyed to ascertain their perceptions of the level of news literacy demonstrated by their schools' students. Forty-one respondents indicate a need for news literacy instruction, but they also indicated that little curriculum attention was given to that need. Moreover, teacher librarians and classroom teachers need training on news literacy. Fake news is a wake-up call to educators and the community at large to gain competency in critically analyzing fake news in particular, and information in general.
\end{abstract}

Keywords: media literacy; curriculum; mass media; critical thinking; journalism

\section{Introduction}

As the recent American Presidential race made abundantly clear, news might not be as true as it appears. At the same time, mass media play an increasingly significant role in today's society. Even when one is not searching for information, mass media permeate everyone's environment, influencing their world view and decision-making. Therefore, people need to consciously and critically analyze and evaluate mass media messages and only then decide how to respond. Otherwise, they will not make reasoned decisions, and they will suffer the consequences of their assumptions or ignorance. They must be news literate.

While news literacy is a lifelong skill, the logical time to start teaching such literacy is in K-12 educational settings so that all people have the opportunity to learn and practice news literacy. The age to begin such instruction varies, with some asserting that students as young as kindergarteners can analyze news (Moore, 2013; Share, 2015).

This study investigates the needs for K-12 students to be news literate, and their current level of skills, as perceived by in-service teachers and school librarians. The findings inform the development of news media literacy curriculum that can be implemented by K-12 teachers and school librarians.

\section{Need for News Literacy}

The high profile of fake news reveals underlying trends in the production and consumption of news.

*Corresponding author, Lesley Farmer, California State University Long Beach, UNITED STATES, E-mail: Ifarmer@csulb.edu 


\subsection{Changes in the News}

The issue of news literacy has become critical nowadays. A recent Atlantic article suggests several reasons why (Thompson, 2016). People have put less trust in mainstream news outlets and other public institutions as they have dramatized or hidden certain perspectives. As news media outlets increasingly communicate their messages to narrow target audiences, thanks to hundreds of cable channels, which are less regulated than the handful of "free" basic channels, people can stay in their information "comfort zones" and "filter bubble" (i.e., personalized search results generated by a website algorithm based on prior search behavior (Pariser, 2011)) and not consider different points of view. This filter bubble is increasingly easy to stay within as the advent of social media enables more people add to the news universe - with less vetting, editorial control, or monitoring. Furthermore, with less gatekeeping combined with low overhead costs and instant broadcasting ability, social media give mainstream news outlets a competitive run for their money. Timelines becomes more critical, and partisanship can attract a greater audience, thus jeopardizing traditional news verification and in-depth analysis. The result is an overwhelming amount of news to contend with - and less control on its quality.

\subsection{Fake News}

This daunting situation is further exacerbated by the increasing frequency and sophistication of fake news. In is basic form, fake news is deliberate, publicly published disinformation/hoax/lie purported to be real news, published by established mass media or social media. News may be faked by lies, doctored content (e.g., photo editing, misleading statistics), content that is misleading or taken out of context), counterfeit sources, and false attribution. Fake news is considered is one type of misleading news, which may be created for several reasons: to misinform, for fun, out of passion or strong belief, to gain power or influence, or to get richer.

EAVI, a European commission for media literacy, identified several types of misleading news. Occasionally, media creators make honest mistakes that could hurt a person or organization; normally the creator retracts that mistake and may apologize. "Clickbait" refers to eye-catching headlines and images that use deception to get online users to click on the hyperlink; the actual news may contradict the headline or image (e.g., terms such as "shocking" or "looming", provocative images). Systematic information campaigns such as propaganda may be used by governments to mislead and manipulate people's knowledge, attitudes, or values (e.g., "Buy war bonds," "Stop smoking”). Content is sometimes sponsored, and published as an advertising that looks like editorial or news content; however, the information may signal a conflict of interest with the news outlet. Partisan content reflects ideological interpretation that usually uses emotional language; it may proport to be impartial (e.g., Tea Party or oil industry). Satire is social commentary that typically uses irony, absurdity or humor (e.g., The Daily Show, Mad magazine). Pseudoscience refers to misleading or misrepresented scientific studies with exaggerated or false claims (e.g., snake oil or climate change denial). Conspiracy theory explains a complex reality that provokes fear and rejects experts and refutations, which may be interpreted as evidence that the conspiracy is real (e.g., Kennedy assassination or Twin Towers conspiracy).

Media Matters (2016) explains ways that misinformation can be "weaponized" into fake news. Misleading or information taken out of context can be used to support lies. Satire can be presented as a legitimate news story. Propaganda can include lies, and yet presented as a legitimate news story. Clickbait can include lies, and yet presented as a legitimate news story. Conspiracy theories can be presented as a legitimate news story.

Fake news, per se, is not a new phenomenon. With language comes truth and lies. News, then, reflects both possibilities. With each "new" mass media format -- be it the printing press, radio, television or the Internet -- has come fake news. Stories of exotic travels have been fabricated for centuries. The stock market exchange has suffered because of fake news (Vosoughi, Roy \& Aral, 2018). The Jews have often been the victims of fake news. The critical difference about contemporary fake news is its much expanded and timely 
distribution via the Internet, which then can lead to its greater influence. And fake news is unlikely to go away. Fake news has been the catalyst for political polarization and upheaval, the rise in diseases because of vaccination scares, and killings. When people believe fake news, they are misinformed, and may make poor decisions (Berman, 2017). When people don't know what to believe, they may become frustrated, polarized, confused, fearful, distrustful, cynical, and withdrawn. None of this helps society.

So why do people believe in fake news - and pass it on? The same motivations that drive people to create fake news can apply to those who believe and share it. In other cases, people lack the background knowledge or logical skills to discern the veracity of the information. However, part of the reason for believing fake news lies in the human brain (Sharot, 2017). News is easier to accept if it confirms a person's existing knowledge base. If the news differs from one's current experience, but it is what one wants to believe, then it is more likely to be accepted. For instance, if people hear that poverty will end in ten years, most of them would probably like to believe that news. The opposite is equally true; if it is bad news or news that contradicts strongly held beliefs, then it is likely to be discounted, even if sound evidence is behind it. Furthermore, especially with the increasingly narrow casting of news, people can listen to news outlets that just reinforce existing beliefs so that they do not have to be exposed to opposing point of view - or their favorite news outlet will give convincing arguments against unpleasant news. For instance, a far-left contingency who read Progressive will find many claims about the evil of Donald Trump. This phenomenon is called a filter bubble.

Additionally, as people like to share news, they are more likely to share news that confirms their preexisting beliefs. Social media enables them to broadcast that news, fake or real, more widely and quickly than ever before. While such sharing tends to be sent to friends (e.g., Facebook likes), that news might also be sent to opponents to counter their arguments. Unfortunately, in most cases, that stance will probably be discounted because it does not reinforce their own pre-existing world view. Sharot (2017) suggested that to counter fake news, people can first acknowledge and respect the person who has a different point of view, and not attack the belief system. Then they can reframe that fake news such that common ground or goal can be found in order to improve the situation. It should be noted that it takes both parties to be respectful; otherwise, it is better walk away than to engage in an emotional fight.

\subsection{Students' News Information Behavior}

Youth are likely to get most of their news online or through social commentary television (e.g., The Daily Show) rather than mainstream news outlets, and over two-thirds of teenagers participate at least monthly in social causes (Pew Research Center, 2015). However, today's youth have a growing distrust in mainstream politics, and are the least likely generation to exercise their voting rights. Many youth are dissatisfied with conventional politics and government; they do not like negative campaigns, and think that most politicians ignore them (Bennett, 2008).

These predispositions do not aid in youth's discernment of fake news. More fundamentally, even though teens tend to feel comfortable in the mass media world, they often have poor evaluation skills (Stanford History Education Group, 2016). Furthermore, youth tend to generalize the quality of new sources rather than compare and prefer specific sites based on relative authority (Eysenbach, 2008).

Particularly in the social media arena, youth are not just passing on or commenting on existing news and other information, but they are also generating knowledge (Bennett, 2008). Unfortunately, teen online discussion forums tend to assert personal opinions more than promote respectful and deep deliberation. Such practices can result in a greater spread of fake news rather than its containment.

\subsection{Librarians' Role}

Librarians play a significant role in the information society. They provide physical and intellectual access to information for their communities, and school librarians have a mission to help their school communities 
to be effective users of information and ideas (American Association of School Librarians, 2009).

At the same time that librarians advocate for an open information society, they also think that disinformation "thwarts the development of an informed citizenry" (American Library Association, 2017, p. 1). In its 2017 resolution on access to accurate information, The American Library Association (ALA) encouraged librarians "to help raise public consciousness regarding the many ways in which disinformation and media manipulation are used to mislead the public" (p.1), and supported "the critical role of librarians and library workers in all types of libraries in teaching information literacy skills that enable users to locate information and evaluate its accuracy" (p. 1).

Several articles have focused on school librarians' involvement in news literacy. The September 2018 issue of Knowledge Quest "Fighting Fake News" suggested tools and resources for school librarians to use to combat disinformation. The issue editors assert that school librarians are well qualified to help students discern the validity and accuracy of news, and lead the school community in developing multiple literacy skills. Similarly, in School Library Journal, Linda Jacobson (2017) asserted that school librarians are the best hope in the era of fake news, and she mentioned several efforts that school librarians have made to combat fake news through teaching news literacy.

\section{News Literacy}

What is real? Whom do you trust? No wonder that news literacy is so important.

\subsection{Elements of News Literacy}

News literacy involves accessing, understanding, evaluating, and interpreting news messages. It may be considered a subset of media literacy. What then is media literacy? In the United States, media literacy focuses on the idea of mass media: its purposeful means and end of production. Media in this context refers to information is developed by the mass media, including social media, done for profit/influence/power as its main objective. In that respect, mass media can include periodicals as well as broadcasts, film and video. Mass media often incorporates image, sound and action. Especially because mass media has an agenda, the audience needs to be aware of their purposes, and decide how to respond.

The Center for Media Literacy (2015) developed core concepts related to media messages; students need to consider the process by which the message is made, the message's content and framework, and the intent of the message. The Center further asserts that media have embedded values and perspectives, and are experienced uniquely by each person. Within that framework, news is particularly salient because there is often a perception that news is accurate and trustworthy, an assumption that has been challenged. Media literacy fits well under the umbrella of information literacy, and news provides a concrete basis for discernment (Kahne, Lee, \& Feezell, 2012).

\subsection{News Literacy Education}

In advocating for media literacy education, the National Association for Media Literacy Education (2007) identified six core principles for such education: active inquiry and critical thinking about media, need to address all forms of media, reinforcement of lifelong skills, development of civic engagement, media as part of culture and a socialization agent, individual construction of meaning from media messages.

In her paper on news literacy, Hobbs (2010) recommended that news literacy educators should start with current news that interests learners. Close reading should be introduced to enable learners to understand and analyze/critique. Learners should discuss news using critical questions. Learners should know how news is constructed and link it with analysis. Learners should work with a variety of media, and connect their school experience with community issues. 
Silverblatt, Ferry and Finan (1999) suggested five approaches to teach media literacy: ideological analysis based on cultural studies, autobiographical analysis, nonverbal analysis (paralanguage), mythic analysis (allegories and belief systems), and analysis of production elements such as visual principles and editing practices.

Stony Brook College's Center for News Literacy (www.centerfornewsliteracy.org) offers the most well known news curriculum. The main learning outcomes include the ability to access, evaluate, analyze, and appreciate news. The curriculum teaches the following concepts: the power of reliable information and the free flow of information, the mission of the press and its relation to government, how journalists work and make decisions, the impact of digital revolution and news media structural changes on news consumptions, news and reader responsibility, and why news and its literacy matters. The curriculum units include: distinguishing between journalism and other information providers, distinguishing between news and opinion, distinguishing between assertion versus verification, distinguishing between evidence and inference, deconstructing news based on evidence and source reliability, distinguishing between news media bias and audience bias.

\section{School Librarians' Perceptions of News Literacy}

Ostensibly, school librarians deal with news literacy as part of their mission to help students become effective users of information. In this era of disinformation, what are school librarians' own perceptions about fake news and their perceptions about students' news literacy? Furthermore, what actions are school librarians taking to address fake news?

To answer these questions, the author investigated the perceptions and practices of California school librarians relative to fake news. Specifically, she surveyed this population about their knowledge of fake news, their perceptions of the current level of middle and high school students' news literacy, their perception of needed student news literacy skills, and their current efforts to improve students' new literacy. This project contributes to the field in that it informs school librarians about news literacy, and provides them with curriculum to help middle and high school students learn news literacy concepts and skills.

\section{Methodology}

A survey was used to collect perception information. The instrument itself is based on Stanford's validated questionnaire (Wineberg \& McGrew, 2017), and was adapted editorially to address an adult audience rather than students (replacing "you" with "students"). The initial survey was pilot-tested with a district school librarian, and was modified very slightly for clarification.

The population to survey, K-12 school librarians, was chosen because they work with all students and faculty across the curriculum. More than any other school staff person, school librarians are likely to know students' assignments, information behaviors, and the resources that students consult. In observing students' behaviors and working with the school community, school librarians are likely to be the most knowledgeable about students' news literacy and academic efforts to teach news literacy.

One school district's school librarians served as a district-specific population because the district's library services have a positive reputation within the state. This district serves over 72,000 students in 85 schools in one of the most diversity large cities in the country. Every middle and high school has a credentialed school librarian, and Title I elementary schools are also served by a credentialed school librarian. The school district was also which was chosen to optimize response rate and to determine the possible variance in responses within one large diverse district. A California-wide effort to solicit school librarians was made to compare responses and determine possible generality.

Subjects were recruited via email through the district library services listserv and through CalibK12 (calibk12@googlegroups.com), which is an online email-based Google group that serves as a discussion forum for California school librarians. Users of this Google group do not have to belong to any organization. Subjects agreed to the information consent statement, and completed the online 15-question survey in about ten minutes. The complete survey is available in appendix A. 
The instrument asked survey participants to define "fake news" in order to discern their immediate perception and understanding of the term, which might color their response about related lessons and curriculum that they provided, which were follow-up open-ended questions. Participants were also asked the open-ended question "What information and skills should students have relative to fake news?" to elicit their immediate ties between their understanding of fake news and students' needed understanding of fake news.

In the instrument, participants were asked their perceptions about students' knowledge about fake news in terms of specific news literacy tasks. These tasks consisted of determining tweet trustworthiness, questioning the relative reliability of commercial and newspaper comment posts, distinguishing between a news article and an opinion column, identifying advertising on a news website. For high schoolers, the tasks consisted of comparing a newspaper comment sections, comparing two Facebook exchanges, determining a website's trustworthiness, determining the trustworthiness of a phono posted on a photo-sharing website, and questioning the relative reliability of a sponsored post and a newspaper story. These tasks were directly quoted from the Stanford questionnaire given to middle and high school students (Wineburg \& McGrew, 2017). To develop the questions, the researchers developed a bank of assessment to measure students' civic online reasoning based on best practices, then mapped the domain of civic online reason to identify three core competency constructs: who is behind the information, the evidence presented, and competing sources. They then developed and tested prototype tasks to measure the constructs in terms of their goodness-of-it for cognitive validity. They did not design the tasks for specific grade levels, but rather to match middle school students' and high school students' range of online reasoning. In that respect of range, this study also asked for middle or high school level rather than specific grade level.

\section{Findings}

Forty-one school librarians completed the survey: 2 in elementary schools, 2 in K-8 schools, 15 in middle schools, and 22 in high schools. Of the 41 respondents, 31 worked in the one targeted school district. The rest of the respondents worked in other school districts in California. The number of respondents lessens the probability that a significant difference would exist between the responses from the one district and the rest of the state; indeed, they were in sync. However, the low response from the rest of the state limits any generalizability of the findings.

The definitions of fake news by the respondents did not differ significantly by school level or district. About half of the school librarian respondents' definition of fake news aligned with the study's definition. Another third defined fake news as misleading news. Six defined fake news as being unverified news, two defined fake news as deceptive news, and two stated that they had not heard of the term until Donald Trump became high profiled.

The ratings were given points along a Likert ordinal scale as follows: not well at all $=1$, slightly well $=2$, moderately well $=3$, and very well $=4$ (Stanford, 2016). The ratings for each item were averaged for middle school, high school, and the total 39 respondents (the two elementary school responses were omitted as the tasks were designated for middle and high school students). While a Likert scale is ordinal, not scalar, the means can determine relative rankings.

In rank order, with the highest level of competence first, for both levels, the tasks were:

1. Identifying ads

2. Distinguishing between news and opinion

3. Comparing news comments

4. Identifying trusted websites

5. Determining suitability of a news comment for research

6. Considering the relative strength of evidence of Facebook postings

7. Determining the trustworthiness of a tweet

8. Explaining why sponsored content might not be reliable

9. Distinguishing news versus sponsored content (sponsored reliability was harder for middle schoolers)

10. Determining the trustworthiness of a photograph 
Table 1: Respondents' perceptions of students' degree of news literacy

\begin{tabular}{llllll}
\hline TASKS & \multicolumn{2}{c}{ FREQUENCY $\times$ COMPETENCY LEVEL } & & \multicolumn{2}{c}{ MEAN } \\
\hline & Middle School Librarians & High School Librarians & MS & HS & Merge \\
\hline Tweet trustworthiness & $0 \times 4+1 \times 3+12 \times 2+4 \times 1$ & $0 \times 4+5 \times 3+9 \times 2+8 \times 1$ & 1.82 & 1.86 & 1.85 \\
Sponsor reliability & $0 \times 4+0 \times 3+12 \times 2+5 \times 1$ & $0 \times 4+4 \times 3+10 \times 2+8 \times 1$ & 1.71 & 1.82 & 1.77 \\
News comment for research & $0 \times 4+1 \times 3+12 \times 2+4 \times 1$ & $0 \times 4+4 \times 3+12 \times 2+7 \times 1$ & 1.82 & 1.95 & 1.90 \\
News vs. opinion & $0 \times 4+9 \times 3+4 \times 2+4 \times 1$ & $0 \times 4+7 \times 3+13 \times 2+2 \times 1$ & 2.29 & 2.23 & 2.26 \\
Ad on news website & $1 \times 4+11 \times 3+4 \times 2+1 \times 1$ & $3 \times 4+9 \times 3+10 \times 2+0 \times 1$ & 2.71 & 2.73 & 2.72 \\
Compare 2 news comments & $0 \times 4+4 \times 3+10 \times 2+3 \times 1$ & $0 \times 4+5 \times 3+12 \times 2+5 \times 1$ & 2.06 & 2.00 & 2.03 \\
Website trustworthiness & $0 \times 4+3 \times 3+11 \times 2+3 \times 1$ & $0 \times 4+5 \times 3+12 \times 2+5 \times 1$ & 2.00 & 2.00 & 2.00 \\
FaceBook evidence & $0 \times 4+4 \times 3+7 \times 2+6 \times 1$ & $1 \times 4+1 \times 3+14 \times 2+6 \times 1$ & 1.88 & 1.86 & 1.87 \\
Photo trustworthiness & $0 \times 4+2 \times 3+7 \times 2+8 \times 1$ & $0 \times 4+1 \times 3+8 \times 2+13 \times 1$ & 1.65 & 1.45 & 1.54 \\
News vs. sponsored content & $0 \times 4+1 \times 3+12 \times 2+4 \times 1$ & $0 \times 4+3 \times 3+12 \times 2+7 \times 1$ & 1.82 & 1.68 & 1.72 \\
\hline
\end{tabular}

The number of respondents required parametric statistics. Chi-square statistics found no significant difference between the competence means of middle and high school students.

In answering the open-ended survey question about fake news-related lessons that respondents provided, the following topics were mentioned, listed here in rank order by frequency of mentions.

Table 2: Rank order of fake news-related lessons for students as mentioned by respondents

\begin{tabular}{lll}
\hline RANK ORDER & COMPETENCY & NUMBER OF TIMES LESSON MENTIONED \\
\hline 1 & Evaluate sources & 14 \\
2 & Differentiate between true and fake news & 10 \\
3 & Determine the reliability and accuracy of sources & 7 \\
4 & Read and think critically & 7 \\
5 & Identify reliable sources (e.g., subscription databases) & 4 \\
6 & Identify the author/creator of a sources & 3 \\
7 & Distinguish between fact and opinion & 3 \\
8 & Identify bias & 2 \\
9 & Identify sponsored sources & 2 \\
\hline
\end{tabular}

Single mentioned competencies included: information literacy, citing sources accurately, identify edited/faked photos, how news is created, history of fake news, consequences of fake news, journalism. Generally, no differences between middle and high school librarians' responses were found in the types of competencies mentioned. However, high school librarians were more likely to provide lessons on reliable sources and databases while middle school librarians were more likely to provide lesson on evaluating websites. Nine librarians provided no lessons. In one case, the librarian mentioned doing a fake-related lesson in response to a teacher's request.

When asked if a fake news curriculum existed at their sites, four middle school librarians stated that they developed a curriculum and used it independently, one elementary school had a curriculum, in one high school half of the freshmen received a fake news curriculum, and in one middle school site the teachers generated a curriculum without collaborating with the librarian. The other 34 librarians stated that no such curriculum existed. 


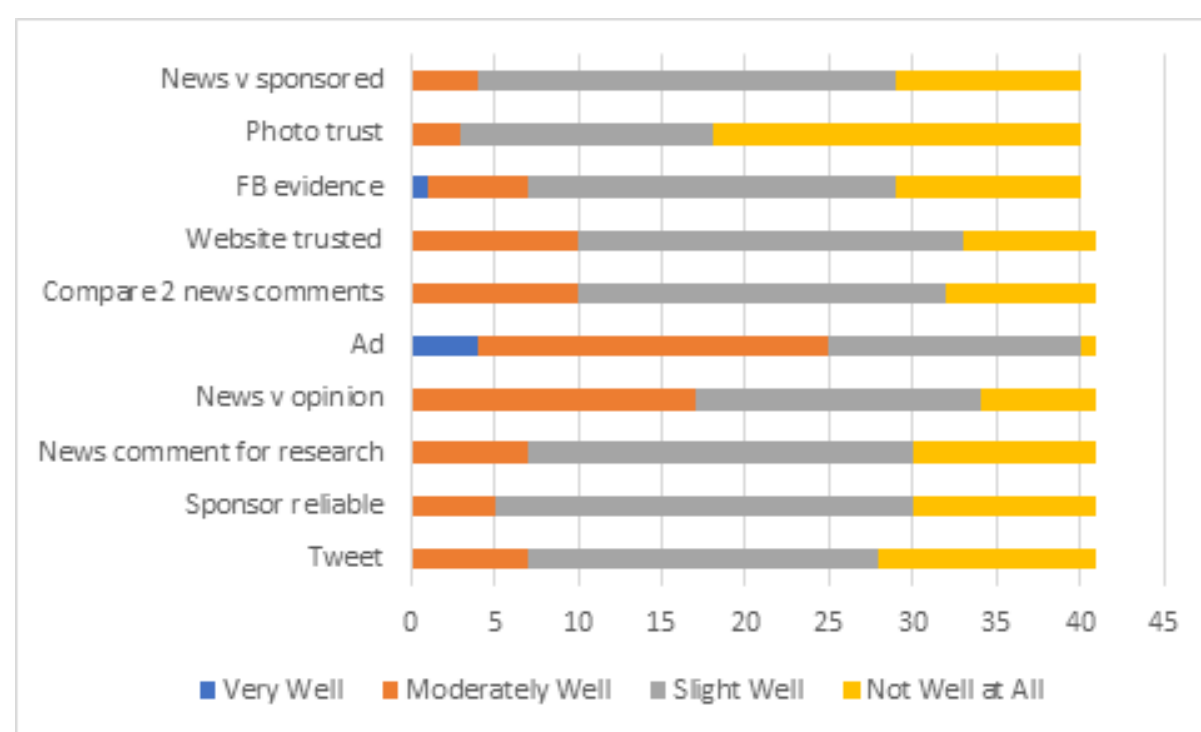

Figure 1: Respondents' perceptions of students' degree of news literacy

\section{Discussion}

The survey revealed the status of K-12 students' news literacy and their need for news literacy instruction, as perceived by California school librarians.

All of the school librarian respondents knew about fake news, with about half of them articulating the full description of fake news. The remaining respondents identified partial aspects of fake news: being misleading or deceitful, missing verifying resources, aiming to sell or otherwise influence. No significant difference existed between middle and high school librarians in defining fake news. One respondent listed almost all of the types of misleading information that EAVI addressed. For students to identify fake news, their teachers, including school librarians, need to be clear about the definition of fake news.

Overall, school librarian respondents thought that their school's students performed "slightly well" relative to news literacy. As that data in Table 1 indicated, no significant difference in competency level existed between middle and high school students, as perceived by the associated school librarians. Perhaps because news literacy is often not explicitly addressed in California's K-12 language arts curriculum, it is unlikely that students would learn specific news literacy skills.

Both middle and high school librarian respondents stated that students were most competent at distinguishing advertisements and least proficient at discerning the trustworthiness of photographs. The relative ranking of the news literacy skills revealed that students were more proficient in distinguishing between types of news than they were in determining the relative trustworthiness and quality of news content, especially news in social media. The former entails comparing features between two subformats, while the latter requires analyzing the content within a source, which is a more nuanced process. Particularly as sponsored content can very closely mimic non-sponsored content, it is not surprising that students would have difficulty distinguishing the content quality between the two new origins. This finding reinforces the Stanford study's conclusions. The fact that trusting photographs was the least proficient area also points out the need for visual literacy, a set that skills that are seldom addressed systematically in academic curriculum (Silverman \& Piedmont, 2016). Photography also falls under the umbrella of media literacy, which is another neglected curricular area.

Analysis of the news literacy lessons provided by both middle and high school librarian respondents reveal traditional information literacy skills: critical thinking; evaluating sources, including determining accuracy, reliability, authorship, and bias; identifying reliable sources such as databases; distinguishing between fact and opinion. Middle school librarians more often than high school librarians mentioned 
teaching website evaluation skills, and high school librarians were more likely than middle school librarians to mention teaching about reliable sources. High school librarians more often than middle school librarian taught about databases; high schools are more likely to subscribe to online databases than middle schools so this finding is reasonable. Two respondents mentioned two skills that focuses on fake news: differentiating between true and fake news, and identifying sponsored sources (although the latter applies to other types of information). Since this question was posed after the respondents answered the questions about students' competencies, the respondents were probably leveraging that information. Visual and media literacies were each mentioned only once. While a case can be made that information literacy includes visual and media literacies, the fact that evaluating websites was often mentioned (and can just as easily be labelled merely as information literacy) illustrates the need for greater awareness and focused attention on the part of school librarians. For instance, school librarians can link fake news instruction with information literacy; they can incorporate fake news as examples for information literacy instruction, and they can use fake news as a "hook" to garner students' attention, then teach news literacy and generalize it to media and information literacy.

It should be noted that nine school librarians either did not mention any lessons or they stated that they did not provide fake news-related lessons. In one case, the respondent stated that as a new librarian, other tasks took priority. In two other cases, respondents stated that classroom teachers were too busy to take time for such lessons. Furthermore, the respondents seldom mentioned that they offered lessons in response to a classroom teacher's request. One limitation of the study is that the survey did not ask the respondents to state reasons for not providing such kinds of lessons; future researchers should ask participants the reasons for offering lessons about new literacy - or not offering such lessons; the responses can lead to identifying incentives for teaching these skills.

News literacy is seldom incorporated into California K-12 curriculum; it is only addressed in the California language arts framework in a couple of sample units. Fake news certainly is not mentioned, largely because this term is recent. Moreover, school librarians were not asked about barriers to integrating news literacy into the curriculum. Seven school librarians stated that they offered a fake news curriculum, four of whom developed and implemented it independently. One respondent said that half of the school's freshmen received fake news curriculum, but the developer and instructor were not specified. In only one case did classroom teachers develop and implement a fake news curriculum, and the effort was done without collaborating with the school librarian. The survey did not ask the respondents to detail the curriculum, so the scope and sequence were not ascertained.

Analysis of responses revealed a positive correlation between students' news competence and the provision of fake news-related lessons, based on the co-occurrence of perception of news competence level and lessons offered. Its significance could not be quantitatively determined, nor could a causal relationship be inferred. Perhaps those school librarians who taught such lessons saw evidence of students' news literacy, which might not be inferred without such instruction. Alternatively, school librarians who were aware of the need for fake news and addressed that need might be more conscious of students' learning in that area.

\section{Conclusions}

This exploratory study focused on California K-12 school librarians' perceptions of their schools' students' news literacy status and needs, and found out what efforts school librarians made in offering instruction about fake news. The study is limited in that the number of respondents was less than 50 , with the majority working in a single district that is known for providing above-average library services. Moreover, students' news literacy levels were ascertained by school librarians' perceptions, which might be biased, although their observations might be more valid than a student's own self-reporting. Nevertheless, these respondents' perceptions about students' news literacy echo the findings of the 2016 Stanford study. For example, less than ten percent of respondents thought that students could perform moderately well, and none thought students could do very well, on trusting photos; in the Stanford study, less than twenty percent of students 
questions the source of the tested post. Stanford students had difficulty evaluating tweets, just as the California respondents noted about their schools' students.

Possibly because the term "fake news" is relatively new in terms of the public's awareness, it is not surprising that students' news literacy was about at the same degree of competency regardless of grade level. In this period of growing awareness, some concepts and skills may need to overlap grade level instruction, with the distinguishing factors being developmentally appropriate content and analysis.

School librarians expressed a need for news literacy instruction, and generally identified generic information literacy skills. However, it became apparent that explicit instruction in visual and media literacies are also needed. Students need to know how to access, interpret, evaluate, and respond to news in its various forms. They need to understand how news and other mass media are produced, and the critical features of each medium. They should also be encouraged to participate in generating news.

Again, news literacy is seldom integrated systematically into the curriculum; likewise, media and visual literacies also lack curricular attention (Hobbs, 2010; Moore, 2013). Identifying barriers to integrating such news literacy would be a useful area for research. As noted above, as information professionals and as teaching faculty, school librarians constitute the obvious source of expertise and instruction. Nevertheless, many school librarians themselves need more specialized knowledge about news, media and visual literacies (Jacobson, 2017; Southworth, 2014).

In short, fake news is a wake-up call to educators and the community at large to gain competency in critically analyzing fake news in particular, and information in general. Students need explicit instruction in critically analyzing news, visual messages, and mass media. However, educators themselves also need instruction in these literacies so they have the competence to integrate them into the curriculum. Once they have such expertise, school librarians are well positioned to leverage the hot topic of fake news to highlight the importance of information and media literacy, and incorporate it systematically into the school's curriculum so that students will be better prepared as informed citizens.

\section{References}

American Association of School Librarians. (2009). Empowering learners. Chicago, IL: American Library Association.

American Library Association. (2017). Resolution on access to accurate information. Chicago, IL: American Library Association. http://www.ala.org/advocacy/intfreedom/statementspols/ifresolutions/accurateinformation

Bennett, W. (2008). Changing citizenship in the digital age.” In W. Bennett (Ed.), Civic life online: Learning how digital media can engage youth (pp. 1-24). Cambridge, MA: The MIT Press, 2008.

Berman, N. (2017). The victims of fake news. Columbia Journalism Review, 56(2), 60-67.

Center for Media Literacy. (2015). Literacy for the 21st century ( $2^{\text {nd }}$ ed.). Malibu, CA: Center for Media Literacy.

EAVI. (2017). Beyond fake news: 10 types of misleading news. Brussels: EAVI.

Eysenbach, G. (2008). Credibility of health information and digital media: New perspectives and implications for youth. In M. Metzger \& A. Flanagin, Eds., Digital Media, Youth, and Credibility (pp. 123-154). Cambridge, MA: MIT Press.

Hobbs, R. (2010). News literacy: What works and what doesn't. Paper presented at Association for Education in Journalism and Mass Communication, Denver, August 8.

Jacobson, L. (2017). The smell test. School Library Journal, 63(1), 24-28.

Kahne, J., Lee, N., \& Feezell, J. (2012). Digital media literacy education and online civic and political participation. International Journal of Communication, 6, 1-24.

Knowledge Quest, 47(1).

Leu, D.J., Forzani, E., Rhoads, C., Maykel, C., Kennedy, C., \& Timbrell, N. (2015). The new literacies of online research and comprehension: Rethinking the reading achievement gap. Reading Research Quarterly, 50(1), 1-23.

Moore, D. (2013). Bringing the world to school: integrating news and media literacy in elementary classrooms. Journal of Media Literacy Education, 5(1), 326-336.

National Association of Media Literacy Education. (2007). The core principles of media literacy education. New York, NY: National Association of Media Literacy Education.

Pariser, E. (2011). The filter bubble: How the new personalized web is changing what we read and how we think. New York, NY: Penguin.

Pew Research Center. (2015). Millennials \& political news. Washington, DC: Pew Research Center.

Rheingold, H. (2012). Stewards of digital literacies. Knowledge Quest, 41(1), 52-55.

Share, J. (2015). Media literacy is elementary: Teaching youth to critically read and create media. New York, NY: Pater Lang. 
Sharot, T. (2017). The influential mind: What the brain reveals about our power to change others. New York, NY: Henry Holt. Silverblatt, A., Ferry, J., \& Finan, B. (1999). Approaches to media literacy. Armonk, NY: M. E. Sharpe.

Silverman, K., \& Piedmont, J. (2016). Reading the big picture: A visual literacy curriculum for today. Knowledge Quest, 44(5), 32-37.

Southworth, A. (2014). Visual rhetoric for school librarians. School Library Monthly, 31(3), 36-38.

Stanford History Education Group. (2016). Evaluating information: The cornerstone of civic online reasoning. Palo Alto, CA: Stanford University.

Thompson, D. (2016). Why do Americans distrust the media? Atlantic, 318(2). https://www.theatlantic.com/business/ archive/2016/09/why-do-americans-distrust-the-media/500252/

Vosoughi, S., Roy, D., \& Aral, S. (2018). The spread of true and false news online. Science, 359(6380), 1146-1151.

Wineburg, S., \& McGrew, S. (2017). Lateral reading: Reading less and learning more when evaluating digital information (Stanford History Education Group Working Paper No. 2017-A1). https://ssrn-com.csulb.idm.oclc.org/abstract=3048994 


\section{Appendix A:}

Thank you for participating in this study, the purpose of which is to examine the perceptions of teacher librarians about "fake news" and its status within your school in order to ascertain the needs for curriculum about fake news. You have been asked to participate in this study because you are a practicing teacher librarian. This questionnaire will take between 5 and 10 minutes to complete. Please read each question carefully and answer them as accurately as possible. The success of the study depends on this.

As a reminder, your participation is entirely voluntary and your responses will be held in the strictest confidence.Ifyouvolunteer to bein thisstudy, youmay withdrawatany time withoutconsequences ofanykind. Participation or non-participation will not affect your employment status or any other personal consideration or right you usually expect. You may also refuse to answer any questions you don't want to answer and still remain in the study. The investigator may withdraw you from this research if circumstances arise which in the opinion of the researcher warrant doing so. Completion of this study serves as your agreement to participate.

\section{Survey Instructions}

Please adhere to the following guidelines when completing the survey:

1. You may also complete the survey at any computer that has Internet access. If you have received this e-mail through your work address, for example, you can complete the survey using your home computer or a public computer. The two requirements for participation in the survey are that you have the URL address and your agreement.

2. I am only interested in your responses that pertain to your library job. If you have another job, do not draw upon this other job in your responses.

3. If you work at more than one library, please provide responses for the job where you spend the most amount of your time.

4. If you would like to participate to a greater extent in this research (about 2 hours of self-assessment and observation), or have questions, please contact the researcher.

\section{FAKE NEWS QUESTIONNAIRE}

What is your definition of "fake news"?

\section{If you work with middle school students:}

Given the following tasks, how well would your school's students perform on an A-F scale, A being best?

Consider tweets and determine which is the most trustworthy:

Read a sponsored post and explain why it might not be reliable:

Examine a post from the newspaper comment section

and explain whether they would use it in a research report:

Distinguish between a news article and an opinion column:

Identify advertisement on a news website:

$\begin{array}{lllll}\text { A } & \text { B } & \text { C } & \text { D } & \text { F } \\ \text { A } & \text { B } & \text { C } & \text { D } & \text { F }\end{array}$

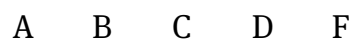

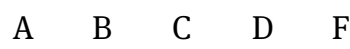

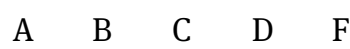

\section{If you work with high school students:}

Given the following tasks, how well would your school's students perform on an A-F scale, A being best?

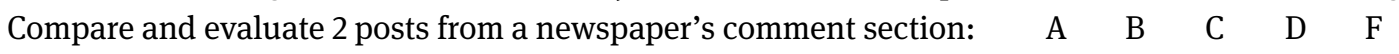

In an open web search, decide if a website can be trusted:

Consider the relative strength of evidence that 2 users present

in a Facebook exchange:

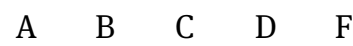

Decide whether to trust a photograph posted

$\begin{array}{lllllll}\text { on a photo-sharing website: } & \text { A } & \text { B } & \text { C } & \text { D } & \text { F }\end{array}$

Determine whether a news story or a sponsored post is more reliable: $\quad$ A $\quad$ B $\quad$ C $\quad$ D $F$ 
What "fake news" related lessons do you give?

What "fake news" curriculum is provided by your school, if you know?

What information and skills should students have relative to "fake news"? 